\title{
La mercantilización de los cuerpos. ¿Paz social entre los hombres, guerra no declarada a las mujeres? ${ }^{1}$
}

\author{
María FERNÁNDEZ EsTRADA
}

Recibido: 15.12 .2011

Aceptado: 13.02.2012

\section{RESUMEN}

En la sociedad del espectáculo, la mercantilización de los cuerpos es presentada como el ejercicio de una "nueva" ciudadanía, inscrita en un transgresor discurso emancipatorio de los cuerpos. La historia de la ciudadanía, desde una perspectiva crítica feminista, ha supuesto la historia de un fracaso por lo que a los derechos de las mujeres respecta ¿Esa "nueva" ciudadanía, promesa en la sociedad del espectáculo, será compatible con la vindicación de nuestros derechos? ¿Es realmente subversiva su propuesta? Reflexionar sobre ello resulta inevitable para el feminismo.

Palabras clave: mercantilización, ciudadanía, contrato, intercambio de mujeres.

\section{The commodification of bodies. Soccial peace among men or undeclared war against women?}

\begin{abstract}
In the society of spectacle the commodification of bodies is presented as the exercise of a "new" citizenship, enrolled in a transgressive emancipatory discourse of bodies. The history of citizenship from a critical feminist point of view has meant the history of a failure regarding to women's rights. Does this "new" citizenship, pledge in the society of spectacle, will be compatible with the vindication of our rights? Is it really subversive its proposal? Thinking about it is inevitable for feminism.
\end{abstract}

Key words: commodification, citizenship, contract, exchange of women.

De un tiempo a esta parte se ha vuelto cada vez más difícil allanar el camino de las investigaciones críticas sobre los asuntos que históricamente han contribuido a la constitución de la teoría feminista. Esta teoría, plural en sus contenidos, baluarte en tiempos ilustrados, termina por entrar en el siglo XXI, tan fuerte y compleja que no sólo multiplica sus contenidos sino que parece disparar su continente en múltiples vértices. Tantas veces encerrada en su armazón teórica, ilusionista en ideas, tantas veces convertida en movimiento social lejos de prisiones académicas.

\footnotetext{
${ }^{1}$ Parafraseando el título del libro de Susan Faludi: Reacción. La guerra no declarada contra la mujer moderna.
} 
Conocedora de esta multiforme dimensión que caracteriza a los verdaderos pensamientos críticos y retada por tal amplitud, he de reconocer , no obstante, que hay veces que la imperiosa necesidad que acucia a mi pensamiento, con el fin de obtener armas adecuadas para ilustrar mi práctica, en busca de interpretaciones capaces de aprehender la realidad, se ve entorpecida. Demasiadas posibilidades para un objetivo: no alcanzo a servirme de las herramientas teóricas y políticas que me brinda gran parte de la apuesta feminista más vanguardista, protagonista del movimiento. La dificultad sur ge incluso para citar las corrientes más transgresoras, el término queer se desliga de manera furiosa de cualquier intento de nombrarlo en tanto que esto o lo otro. Mi empobrecido árbol de Porfirio gira tontamente sin sentido, buscando desesperadamente engranajes conceptuales a los que asirse.

Ignorante, el intento, obsoleto, anticuado y demodé, así se siente mi pensamiento cada vez que ha aspirado, fallidamente, a participar en la comprensión de un discurso siempre otro, siempre inclasificable, nómada, distinto... Un tímido dejarse llevar, en mi caso, se ha visto siempre frenado por una fuerte necesidad de comprensión que golpeaba con un término: confrontación. ${ }^{2}$

Un fenómeno, por encima de otros, se convierte en el epicentro de múltiples miradas: la sexualización de nuestros cuerpos. La plasticidad del asunto resulta tan compleja que parece atravesar en un sinfín de senderos las interpretaciones que el feminismo arroja sobre el mismo. A este respecto, se impone ante mí la dificultad para interpretar tantas y tantas maneras de convertir un cuerpo en un cuerpo ya antes, ya después, ya ahora, sexualizado. No me es difícil dicha tarea en una interpretación feminista de los cuerpos, ahora bien, me resulta sumamente difícil adentrarme en esa interpretación en un afuera, en un no-feminismo... Es entonces cuando aparece con contundencia un paréntesis en el discurrir de los fenómenos, y sus diversas interpretaciones; ese paréntesis lo facilita el término anteriormente expuesto, confrontación. Una sexualización feminista no puede, a la vez y en el mismo sentido, ser una sexualización no feminista, véase, patriarcal. Esto aparece en forma de confrontación y su disolución parece difícil en tanto que mera performance...

\footnotetext{
2 Los términos interpretación y confrontación, sugeridos a partir de la lectura de un artículo breve en donde se hace una analogía entre conceptos terapéuticos y prácticas políticas: «...A los psicoterapeutas nos gusta pensar que la operación que permite que la terapia progrese es la interpretación: una operación analítica por la que lo que el paciente sabe y dice adquiere un significado nuevo que, hasta ese momento era impensable. Pero los psicoterapeutas, realmente, hacemos pocas interpretaciones. Desde luego muchas menos que preguntas. A veces hacemos sólo paráfrasis: nos limitamos a repetir lo que ya se ha dicho, como para dar a entender que nos hemos enterado o intentar que centremos en ello la atención. Otras veces llamamos la atención sobre dos fragmentos contradictorios del discurso, verbal o gestual, del paciente. A eso llamamos confrontación. [...] Si gano una cantidad determinada de dinero trabajando, puedo llegar a pagar a hacienda hasta casi el 50 \%. Si gano la misma cantidad -o un millón de veces más- como beneficios empresariales - aunque no aproveche las oportunidades que esto me ofrece de imputar a mi actividad otros gastos o evadir impuestos -, el máximo está discretamente por encima del $10 \%$. Es posible que sea muy difícil hacer un análisis e interpretar esto. Pero si queda dicho así, a lo mejor alguien se hace alguna pregunta. Y la conversación puede continuar. Hasta hoy los movimientos que han pretendido transformar el mundo se han basado en propuestas de interpretación del orden existente que justificaban la alternativa que proponían. Es posible que los movimientos que han ocupado las calles y plazas del globo en los últimos
} 
Válidas todas las prácticas de sexualización, el transitar feminista por el mundo parece enredarse en la cuadratura del círculo respecto a un fenómeno hartamente complejo, y unidas por un mismo mundo, aquel lleno de mujeres libres, destapamos la caja de Pandora cuando la sexualización de nuestros cuerpos se adentra en la publicidad ${ }^{3}$ del mercado. ¿La mercantilización de los cuerpos sexualizados puede plantearse a partir de la autodeterminación de los mismos? Un erial de definiciones se ve suplantado por una multiplicidad de opiniones de expertas/os, profesionales que abarcan desde la jurisprudencia, la antropología, la sociología, la política... hasta la medicina, la biología... Todas estas opiniones embarcadas en una misma tarea: los derechos de los cuerpos.

Difícil asir con legitimidad dicho fenómeno. Una posibilidad, que no pretende abarcar unívocamente el tema, podría ser la de confrontar dos opiniones que nos interesan, en tanto que despuntan desde colectivos feministas como estandarte de lucha: el derecho (de nuestros cuerpos) a su mercantilización y el derecho (de los mismos) a no ser mercantilizados. Esta confrontación se convierte en objeto de debate desde el momento en que ambas reivindicaciones se erigen en nombre de la libertad sexual ?dentro del contexto feminista, de la libertad sexual de las mujeres.

Así las cosas, se abre una reflexión que no puede ser planteada sin detrimento de su complejidad por la ardua realidad que compone el fenómeno, en un mundo violentamente globalizado, donde los modelos de desarrollo occidental desproveen cotidianamente al planeta de un futuro y a la mayoría de su población de un modo de vida en donde no se vea comprometida su libertad. Un mundo con un modelo de desarrollo que ha devuelto el sueño de la ciudadanía a una noche, donde es tan duro dormir como despertar. Pero también, un mundo donde parece que sus habitantes (esos que configuran el pueblo, no las masas) abren, por fin, un turno de preguntas, cuyas respuestas -siempre las mismas, siempre por descubrir - parecen encontrar tiempo en las calles, los barrios y las plazas.

Un acercamiento a la compleja problemática aquí planteada se limitará a dibujar posibles, ahora sí, interpretaciones, que contribuyan en pequeña medida a la comprensión de lo que irremediablemente entendemos como una confrontación. Pareciera que ésta tiene la forma de un litigio entre cuerpos, pues se nos dibuja un escenario en donde los cuerpos esgrimen sus derechos en tanto que cuerpos, pudiendo servir este enfoque para defender una cosa o la contraria, dependiendo de a qué cuerpo le preguntes. Pareciera que el derecho de los cuerpos ha sustituido al

\footnotetext{
meses carezcan de algo parecido a una de esas interpretaciones. Y que lo que gritan sean sólo preguntas o confrontaciones. Y puede que eso sea su debilidad. Pero también puede que en eso radique su fuerza y su poder terapéutico.» FernÁndez LiRIA, AlBerTo (2011): «De la Psicoterapia a la Economía». Rebelión.org, 10-15-2011. (El autor es psiquiatra.)

3 Publicidad en tanto que esa mercantilización deviene un asunto público (de uno con los otros) por oposición a los asuntos propios (de cada uno consigo mismo).
} 
derecho de, por ejemplo, las ciudadanas. ¿Sería legítimo, en el debate, alejarnos de los cuerpos para acercarnos a las ciudadanas que los sustentan?

Este posible enfoque nos adentraría en otro debate, a nuestro juicio, sumamente entrelazado ${ }^{4}$ con lo expuesto, como es el debate de la ciudadanía. Debate quizás cansado de sí mismo, incluso algo antiguo, obsoleto o demodé ?como el árbol de Porfirio?, y sin embargo irresistiblemente moderno, actual y «callejero»... en estos tiempos difíciles en los que, como comentábamos anteriormente, el futuro se ha vuelto tan pequeño como árido el presente... Alguien insiste en tomar la palabra en la ciudad... No sabemos si perdurará el esfuerzo pero nos resulta inevitable relacionar este ejercicio público de la palabra con la conquista de la ciudadanía.

Para acercarnos a lo que no es más que el intento de plantear una pregunta en forma de confrontación (sobre el derecho de los cuerpos a su mercantilización o el derecho a no ser mercantilizados) dibujaremos un brevísimo esquema que recorra, en relación con lo que nos ocupa, la configuración del proyecto de la ciudadanía, con la intención de averiguar los principios que la fundan. Tal vez así, sin ofrecer respuestas definitivas, podamos, sin embar go, aportar más elementos para dirimir si el ejercicio de la ciudadanía y sus correspondientes derechos se derivan a partir de, por ejemplo, la mercantilización de los cuerpos ?su compra y venta? o si por el contrario las propietarias de los cuerpos deben ostentar su ciudadanía 5 a priori, para así ejercer el derecho a no ser ellas mismas, en sus propios cuerpos, compradas o vendidas.

\section{HISTORIA DE LA CIUDADANÍA: HISTORIA DE UN FRACASO.}

La teoría feminista a lo largo de su recorrido por la historia se ha encar gado de esclarecer el significado de la siguiente coyuntura: a saber , la exclusión de las mujeres de los proyectos éticos y políticos que dibujan la historia de la filosofía. El resultado de esta investigación apunta en una dirección: la exclusión de las mujeres no es algo que suceda a posteriori sino que es el a priori ${ }^{6}$ de esos proyectos éticos

${ }^{4}$ Tal vez podamos decir que la mercantilización de los cuerpos sea un síntoma paradigmático de determinadas coordinadas patriarcales que configuran nuestro orden social. Así, señalar dicho fenómeno pudiera servir como lupa de aumento ante una estructura mucho más amplia y compleja, en donde este asunto sea una de sus múltiples manifestaciones.

${ }^{5}$ La ciudadanía: o bien es un derecho a priori del sujeto que la ostenta, o bien se pospone en el a posteriori de la historia. Veamos a qué nos referimos: por ejemplo, los extranjeros defienden, y exigen, ser tratados como ciudadanos, sin embargo, las leyes de extranjería en su radicalismo xenófobo les excluyen de ese derecho. $\mathrm{Y}$ en la medida en que esas leyes «ceden» ante las «reivindicaciones» de los movimientos sociales, amplían los derechos de algunos de esos colectivos. Esta recuperación de los derechos a posteriori nunca es suficiente, pues está planteada de antemano sobre la exclusión de los extranjeros. Si planteásemos la ciudadanía como un a priori se «vindicaría» el derecho a ejercer la condición de ciudadanos independientemente de la circunstancia histórica, biográfica, de ser extranjeros fuera de nuestra tierra.

6 A este respecto véanse trabajos de la misma autora: «Autoridad como campo de batalla», en Revista Crítica, n 943, Madrid, 2007, pp. 50-54, y «Educación para la ciudadanía como propuesta feminista» en 
y políticos; es, como se dice en filosofía, el principio primero, el fundamento sobre el que se sustenta la configuración de la realidad, es la estructura de las estructuras. Los orígenes -eurocéntricos- de la civilización, protagonistas del imaginario colectivo occidental, se recrean en una imagen: Aristóteles contemplando el busto de Homero. ${ }^{7}$ La humanidad -representada en algún lugar de la lejana Grecia (Atenas, como lugar)- decide «civilizarse» a sí misma, en un acto que reporta lo que de divino hay en nosotros -la capacidad de trascender racionalmente, como diría Aristóteles-. La filosofía, como origen, da esta vuelta de tuerca: las costumbres y tradiciones cantadas mnemotécnicamente en forma de verso por poetas como Homero dejan de ser materia de ley , y con ello se abre una nueva manera de referirse a los asuntos públicos (esos que atañen a todos y a todas). Ya no se hará uso de la palabra oral $^{8}$ transmitida de generación en generación, oráculo de la tradición y la cultura ancestral -comunes a todos aquellos que formen parte de éstas -. Ahora se propondrá una palabra nueva, eco de algo que aún es más común a todos y a todas, algo más nuestro que las tradiciones, religiones, ancestros y culturas milenarias, algo común y esencial a cada uno de nosotros, a cada una de nosotras. Una palabra que destronará a Homero cediendo el paso a Aristóteles. Una palabra fruto de la razón... Una palabra que podrá escribirse y no solo memorizarse, que podrá ser pensada y no solo recitada. Una manera de decir que llenará el cielo de preguntas, se dibuja, por tanto, la posibilidad de un cielo no solo habitado por dioses, sino un cielo pensado por Aristóteles, Hypatia... Ptolomeo... Copérnico... más o menos acertado, pero, al fin y al cabo, un cielo pensado, no ya rezado o imaginado. Esta manera de pensar el mundo - a lo que se podrían añadir otros orígenes que transgredieran nuestra mirada eurocéntrica- implicaba también una manera distinta de habitarlo: esa nueva manera -resumiendo siglos de historia, en este brevísimo apunte sobre el asunto-podríamos llamarla ciudadanía.

En el mundo, y cada uno en el pequeño apartado en el que le ha tocado en suerte vivir, se pueden hacer dos cosas: sobrevivir o vivir dignamente. Grecia, para ese imaginario colectivo que llamamos cultura occidental, supuso el origen de la segunda, del vivir dignamente, lo que convertía a los habitantes -varones-. de un lugar en ciudadanos, y no en meros supervivientes. Ahora bien, contestar a la pregunta de si alguna vez la humanidad ha sido capaz de dar ese paso en todo su conjunto, nos resulta cuando menos superfluo en un momento en donde la indignación pide, respetando turnos de palabra, el derecho no a sobrevivir sino a una vida digna, constituyente de ciudadanía. Pero a lo que sí queremos contestar es a la pregunta que incordiaría, no ya a la realidad - cuya crudeza, carente de ciudadanía,

Educación para la ciudadanía, Cuaderno de Educación no sexista, nº 23. Instituto de la Mujer . Ministerio de Trabajo y Asuntos Sociales, 2007, pp. 89-109.

7 Cuadro de Rembrandt en donde la figura de Aristóteles aparece en el centro revestida de luz, por oposición al busto de Homero, quien en un segundo plano... parece abandonar el lugar principal. De aquí que una posible interpretación sea la que nos brinda el paso de una explicación poética - no estrictamente racional- a una explicación filosófica - aproximativa a la ciencia- por lo que al mundo de los fenómenos se refiere.

8 Véase Havelock, 1994. 
salta a la vista - sino a la teoría, a toda esa vasta teoría que configura, desde Grecia, nuestra historia del pensamiento con proyectos emancipatorios, críticos y revolucionarios, empeñados fielmente en la defensa de un mundo mejor, más justo, más igualitario, en la defensa de un mundo capaz de ser el hábitat ilustrado de la ciudadanía.

La teoría feminista, como teoría crítica, ejercita responsablemente el derecho a historizar ${ }^{9}$ la historia del pensamiento, a objetivar ${ }^{10}$ las objetivaciones imperantes, de resultas de ello obtenemos que el esfuerzo teórico de los grandes pensadores concurre por igual en un a priori: la exclusión de las mujeres del proyecto de la ciudadanía. Una amplísima bibliografía ${ }^{11}$ feminista da cuenta de cómo, cada vez que los pensadores se dedicaron a la configuración de un espacio público alber gador de democracia, Derecho, legalidad y ciudadanía, se hizo, sine qua non, a la vez y en el mismo sentido que se excluía a las mujeres de ello; valga de ejemplo tanto la democracia ateniense como el contrato moderno. Desde Aristóteles hasta Rousseau, tenemos no ya en tiempos del primero una sociedad, además de esclavista, patriarcal y en tiempos del segundo una sociedad, además de colonialista, patriarcal; sino que tenemos la configuración de toda una cultura y civilización asentada sobre un fuerte paradigma, el de la distinción sexual. En la Grecia clásica los esclavos y los metecos eran excluidos por su condición de hombres no libres y de no atenienses, respectivamente, pero si en el devenir de la historia así lo batallaran, se les devolverá, a unos, la libertad, y a los otros se les reconocerán sus derechos independientemente de su extranjería, transitando con ello hacia la ciudadanía. Las mujeres, excluidas de la ciudadanía en tanto que mujeres, ¿cómo se verán liberadas de su condición de mujeres?

Muchas estructuras de dominación han sustentado los proyectos políticos occidentales, los sistemas esclavistas, segregacionistas, coloniales y raciales, pero solo una de ellas perdura en todos los casos como eterna condición de posibilidad, como eterna condición trascendental, que configura, sin participar , una experiencia: la experiencia política. Históricamente lo que de humano hay en nosotros se ha constituido a partir de la exclusión de las mujeres a esa misma condición, destinán-

9 «[...] hay que preguntarse, en efecto, cuáles son los mecanismos históricos responsables de la deshistorización y de la eternización relativas de las estructuras de la división sexual y de los principios de división correspondientes. [...] es preciso reconstruir la historia del trabajo histórico de deshistoricización o, si se prefiere, la historia de la (re)creación continuada de las estructuras objetivas y subjetivas de la dominación masculina que se está realizando permanentemente, desde que existen hombres y mujeres, y a través de la cual el orden masculino se ve reproducido de época en época» (Bourdieu, 2000: 9, 104).

10 «Al estar incluidos, hombres y mujeres, en el objeto que nos esforzamos en delimitar, hemos incorporado, como esquemas inconscientes de percepción y de apreciación, las estructuras históricas del orden masculino; corremos el peligro, por tanto, de recurrir , para concebir la dominación masculina, a unos modos de pensamiento que ya son el producto de la dominación. Sólo podemos confiar en salir de ese círculo si encontramos una estrategia práctica para efectuar una objetivación del tema de la objetivación científica» (Bourdieu, 2000: 17).

11 Valga como punta de lanza el excelente trabajo de desvelamiento - en su amplísima obra-, tanto en su contenido histórico como filosófico, de la teórica feminista Celia Amorós. 
donos a una inmanencia existencial que, sin querer renunciar a eso que somos, sin embargo ha supuesto de manera constante la privación de nuestra propia propiedad, libertad e independencia. Lo que de humano hay en nosotros, esa animalidad política -que definiera Aristóteles- se ha llevado a cabo a partir de la resolución de lo que además de humano hay en nosotros -la reproductividad, la mortalidad, el tiempo cíclico ${ }^{12}$ de los asuntos propios, siempre hechos, siempre por hacer...- por parte de las mujeres. Eso que hay en nosotros de naturaleza y cultura, se ha distribuido, una y mil veces, de la misma manera: un animal político sólo será político en la medida en que su animalidad ha sido, ya, siempre, resuelta, un hombre mortal, sólo podrá tratarse a sí mismo como inmortal - sueño racional aristotélico-si su mortalidad ha sido, ya, siempre, resuelta. Ese trabajo enteramente cultural de ocuparse de lo que de natural, animal y mortal hay en nosotros, ha sido un trabajo históricamente, y no sin violencia, asignado a la culturalmente construida naturaleza de las mujeres.

\section{Este fracaso de la ciudadanía, tan escuetamente esbozado, debe sumar en su haber una circunstancia histórica que dimensiona con amplitud la inverosimilitud ${ }^{13}$}

12 No me resisto a ilustrar esta posible descripción de un orden distributivo patriarcal con una pequeña anécdota reciente. El 11 del 11 del 11, es decir, el 11 de noviembre de 2011, las noticias de TVE emitieron en su edición de mediodía un pequeño reportaje con motivo de la lotería vendida para tal día ?capicúa por excelencia?. Preguntaban en la calle a distintas personas respecto al día que era, y si habían comprado lotería... Una de las personas preguntada resultó ser un señor de mediana edad, a quien le dicen «¿Sabe usted qué día es?», a lo que el señor responde «¿Eh? No, no, esas cosas las lleva mi mujer. Sí, no sé, ella lleva todo eso, yo me ocupo de las cosas importantes». Qué curiosa percepción de la realidad en donde uno puede dedicarse a las cosas importantes, mientras un asunto como el día en el que uno se encuentra, pasa a ser algo menos importante, no relevante, y desde esa ausencia de valor pasa a ser asunto de mujeres. El tiempo, y su periodicidad; el orden de los días en los que uno por mucho que no lo conozca también se halla, pasa, para este señor a ser un asunto ajeno, femenino, que le permite desentenderse doblemente del tiempo, por lo que a él respecta y por lo que respecta a los demás (véase, por ejemplo, el micromachismo generalizado en las familias donde las madres, o esposas, se acuerdan de todas las fechas señaladas - cumpleaños... - tanto de la familia materna como de la paterna, de los amigos...). Por tanto, podríamos decir que el señor dedicado a las cosas importantes vive desocupado, doblemente desocupado: desocupado de sí mismo y de los otros. Algo parecido a lo que se imponía como requisito en la Grecia clásica, y más tarde en la Modernidad, en donde, una sociedad abiertamente esclavista y patriarcal, la primera, y la otra igualmente patriarcal y colonialista -véase cómo Locke sostenía y defendía la trata de esclavos en las colonias... -, imponía como requisito para poder ocuparse de los asuntos importantes, ya sea la filosofía - y la actividad contemplativa- o la actividad política, tener resueltos los asuntos propios (en tanto que privados, no públicos, que tienen que ver con el cuidado y reproducción de la vida misma). Esa independencia respecto a los asuntos propios permite a los varones percibirse a sí mismos como fuera del tiempo, pues éste no les ata a las tareas caducas, siempre hechas, siempre por hacer, y así desprendidos de sus necesidades mortales, podrán imaginarse inmortales. De lo expuesto, se produce la fícción de que a lo que él (ellos) se dedica es más importante que la condición apriorística de todas las cosas, condición trascendental de la experiencia, como es el tiempo, junto al espacio: imaginamos que, así las cosas, para este señor el asunto espacial, véase, el lugar donde se habita, donde se duerme, donde se come... debe serle totalmente ajeno, ajeno no en tanto que no transite por él, como por el tiempo, necesariamente transitado, pero sí resuelto ya para él. Asuntos resueltos por otra persona, históricamente mujer, considerada en sus quehaceres no importante, irrelevante, siendo sin embargo ese trabajo la condición necesaria de todo lo demás. Paradojas de las percepciones patriarcales.

13 Término empleado por Celia Amorós, véase a este respecto Amorós, 1997: cap.1, «Por un sujeto verosímil», y cap. 3, «El feminismo: senda no transitada de la Ilustración». 
de dicho proyecto. Forzosamente, en el quehacer de los filósofos, reconocemos un denominador común, desde Aristóteles hasta Rousseau, las propuestas políticas que tengan que ver con la emancipación del individuo, con su libertad y derecho a un orden civil exento de dominación, implicaban más o menos abiertamente -dependiendo del filósofo- una contradicción in terminis, pues se asentaban sobre la acrítica dominación masculina. Ésta, pareciera perdurar exenta de hermenéuticas reformistas, libre de sospechas, anclada en el orden de la naturaleza, saltaba al orden del discurso perenne, impertérrita, siempre arrastrando las mismas premisas, adaptadas para cada ocasión, pero con los mismos efectos perversos para la vida de las mujeres. Pues bien, la teoría feminista, ${ }^{14}$ una vez más, señala las verdaderas circunstancias históricas que acompañaron a los procesos políticos, como es el caso, tan estudiado, de los teóricos del contrato. Al mismo tiempo, pero no en el mismo sentido, que el contractualismo moderno se abrió toda una serie de discursos empancipatorios, ilustrados, y ciertamente verosímiles -en lo que a su coherencia respecta- que figuran como interlocutores -invisibilizados por la tradición del pensamiento escrito con mayúsculas -: Mary Wollstonecraft, Ollympe de Gouges, Condorcet... y más tarde figuras como Marie Deraismes... De aquí que la ignominia teórica -en su discurso-, y práctica -en su quehacer-, sea doblemente condenada. La Modernidad no solo se traicionó a sí misma, al presuntuoso espíritu ilustrado, sino que podría haberse escrito (realizado) de otra manera, existió esa posibilidad y sin embargo se optó por escribir (realizar) una ilustración inverosímil.

Así las cosas, se amplía la sospecha desde la Grecia clásica hasta la Francia revolucionaria: pasaríamos del fracaso a priori de la ciudadanía a la ficción del contrato moderno. Veámoslo. ${ }^{15}$

\section{DE LA FICCIÓN DE LOS PRINCIPIOS DEL CONTRATO MODERNO}

El contrato sexual, ${ }^{16}$ ensayo de la teórica feminista Carole Pateman, expone claramente cómo los contractualistas modernos sustituyeron el patriarcalismo tradicional, la ley del padre, por el patriarcado moderno, en la fórmula fraternal del contrato social. La retórica contractual de los filósofos políticos ilustrados reviste un orden de subordinación bajo una forma contractual: el matrimonio. Al derogarse la ley del padre - del patriarcalismo tradicional- se creyó zanjado el orden jerárquico patriarcal. Esto sucede de tal manera que, por ejemplo, Locke llega a ser considerado antipatriarcalista por algunos historiadores:

14 Véanse Puleo, 1993 y Amorós, 1994, 1997.

15 La reflexión que continúa, por lo que respecta a los tres apartados siguientes, forma parte del trabajo inédito de la autora de este artículo. Fernández Estrada, María (2009): Hacia un análisis de las estructuras fundamentales del patriarcado contemporáneo. Trabajo de investigación inédito tutelado por la profesora Celia Amorós Puentes, realizado con vistas a la obtención del Diploma de Estudios Avanzados.

16 Pateman, 1995. 
«\&52. Quizá pueda reprocharse como crítica que está fuera de lugar en un tratado como éste el que yo ponga en tela de juicio palabras y nombres que ya han sido aceptados en el mundo. Sin embargo, tal vez no resulte disparatado ofrecer términos nuevos cuando los viejos pueden hacer que los hombres saquen conclusiones erróneas. Tal cosa ha sucedido, probablemente, con la expresión "poder paternal", la cual parece que da al padre todo el poder que un matrimonio tiene sobre sus hijos, como si la madre no tuviera parte en ello. Mas si consultamos con la razón o con la Revelación, descubriremos que la madre tiene el mismo derecho que el padre. Esto puede darnos motivo para que nos preguntemos si, en vez de decir "poder paternal", no deberíamos llamarlo "poder de los padres"; pues toda obligación que la naturaleza y el derecho generacional imponen a los hijos debe ciertamente, hacer que éstos se sometan igualmente a sus dos progenitores.» 17

\section{Y a continuación leemos en el capítulo séptimo, «De la sociedad política o civil»»:}

«82. Pues sucede que el marido y la mujer, aunque tienen una preocupación en común, poseen sin embargo entendimientos diferentes; y habrá casos en los que, inevitablemente, sus voluntades respectivas habrán de diferir. Será por tanto necesario que la última decisión, es decir, el derecho de gobierno se le conceda a uno de los dos; y habrá de caer naturalmente del lado del varón, por ser éste el más capaz y el más fuerte.»18

Pateman explica, muy claramente, cómo derrocar la ley del padre ?el derecho paternal? no implica derrocar el patriarcado, pues el derecho paternal no es más que una dimensión del derecho patriarcal y acontece sólo después de que el hombre devenga esposo de una mujer ?derecho sexual/conyugal?. El patriarcado ya no será paternal, la sujeción de las mujeres pretendida por los varones no viene dada en tanto que estos son considerados padres, sino en tanto que son considerados simplemente varones. «El contrato moderno tiene lugar después de la derrota política del padre y crea el patriarcado fraternal moderno.»19

Tras lo expuesto, ¿derrocar la ley del padre supuso derrocar el patriarcado? Pudiera parecerlo en la medida en la que la sociedad civil moderna se inaugura como la sociedad que abandona el principio de autoridad. Pareciera, por tanto, que el derecho político es incompatible con el derecho paterno, y de hecho así lo es: el proyecto rousseauniano educa a un hombre, que en el sentido kantiano, se emancipa de su autoculpable minoría de edad, y se atreve a pensar -sapere aude ${ }^{20}$, se rebela contra el principio de autoridad, y conquista las libertades que dan lugar a la teoría del contrato social. Ahora bien, esto no tiene por qué significar, y de hecho

17 «Del poder paternal», capítulo sexto del Segundo Tratado sobre el Gobierno Civil (Locke, 2002).

18 LOCKE, JOHN: «De la sociedad política o civil», en op. cit. (El subrayado es nuestro.)

19 Cfr. Pateman, 1995: 100-101.

20 Véase, respecto a la máxima ilustrada, KANT, INMANUEL (1978): ¿Qué es la Ilustración? En Filosofía de la Historia. México: Ed. Fondo de Cultura Económica. 
no significa, que el derecho político moderno sea incompatible con el derecho patriarcal. Como aclaramos antes, el derecho paterno es sólo una modalidad dentro del derecho patriarcal. Siguiendo la tesis de Pateman, podríamos afirmar que la teoría del contrato es el medio por el cual no se derroca el patriarcado sino que se funda el patriarcado moderno.

En este contexto, por tanto, las mujeres no son parte firmante del contrato originario, sino objeto de ese contrato. Ahora, el a priori de la ciudadanía, del que venimos insistentemente hablando, como es la exclusión de las mujeres de la categoría de individuo (requisito, ${ }^{21}$ sin embargo, para la ciudadanía) tiene, por fin, expresión legal y social: el matrimonio o sujeción conyugal, pues el reverso del contrato social es el contrato sexual.

El significado político de la esfera pública moderna no proviene de su oposición con el derecho paternal -como pensó Locke -, sino por oposición a la sujeción natural de las mujeres. Podríamos señalar con Pateman, que esta sujeción natural de las mujeres se presentaría como uno de los orígenes de la civilización, de la sociedad civil, de la cultura. Podríamos señalar, por tanto, que se trata de los orígenes de la civilización patriarcal, de la sociedad civil patriarcal y de la cultura patriarcal. $^{22}$

Tanto Locke como Hobbes, pese a sus diferencias, señalan que la relación entre los sexos debe atenerse a la relación «natural» entre los cónyuges, donde la mujer debe sujeción al marido. Rousseau, a su vez, pese a las diferencias con Locke y Hobbes, sostiene lo mismo. Ni Rousseau ni Locke consideran que la subordinación de la mujer es un ejemplo de dominación política y de subordinación, si bien el discurso de Hobbes reconoce la subordinación política de esa relación aunque no duda en ningún momento que ese es el orden de cosas que mejor corresponde al funcionamiento de la sociedad civil. Los tres entienden que el orden de la sociedad civil está asegurado, o depende, del derecho de los maridos sobre sus esposas. 23 Pateman aclara por qué el derecho conyugal se ve como no político, a saber: es la manera de evitar su cuestionamiento desde el análisis que discute cualquier poder absoluto como ilegítimo, por ser considerado como no-civil. Por tanto, la mejor manera de imposibilitar ese análisis es declarar el matrimonio como un contrato no político. Puesto que a las mujeres, simultáneamente se las niega y se les concede el poder hacer contratos.

Sigamos detallando qué entraña la idea de contrato. La idea de contrato implica de manera necesaria la idea de individuo, y a su vez ¿qué implica ser un individuo?

21 En tanto que poseedor de su persona firmará un contrato como parte.

22 No ya en el sentido de patriarcado paternal, principio de autoridad del padre, sino patriarcal en el sentido amplio de patriarcado ?principio de dominación de los varones en tanto que varones.

23 Cfr. Pateman, 1995, op. cit. 
Ser propietario de su propia persona. Pateman señala cómo «la tarea del individuo es asegurarse que su derecho de propiedad no sea interferido -como pudiera pasar en el estado de naturaleza-; esta autoprotección se resuelve con el contrato». ${ }^{24} \mathrm{En}$ esta tesitura se ponen en juego por tanto dos conceptos: el concepto de PROPIEDAD, y el concepto de PROTECCIÓN, uno para proteger la propiedad de su persona entra en relación con otros, no ya de manera natural sino contractual. Ahora bien, esto presupone el tercer concepto imprescindible, el concepto de IGUALDAD: «Los hombres entran en relación social sólo si pueden proteger su propiedad no a costa de ella, para esto es necesario que los otros le reconozcan como un igual, el reconocimiento mutuo entre los poseedores de propiedades se logra a través del contrato». ${ }^{25}$

¿Qué diremos frente a esta tríada conceptual? Una tradición como la marxista señala su fracaso debido a las condiciones impuestas por el capitalismo, el capital hace que, a posteriori, fracase este proyecto. Una tradición como la feminista, siguiendo a Pateman, dirá que ese proyecto ya había fracasado a priori. Veámoslo, a saber: en las mujeres la PROPIEDAD siempre está ya perdida, en el estado de naturaleza somos subordinadas naturales y no buscamos la manera de autoprotegernos, sino que accedemos a ser protegidas. Y en el estado civil se perpetúa esa situación. ¿Cómo? Pues como sucede todo en la sociedad civil: contractualmente. «Accedemos al contrato para tener una relación de subordinación con consentimiento, cediendo o dejando invadir nuestra propiedad, no se da el caso que accedamos al contrato para autoprotegernos, sino para ser protegidas.» ${ }^{26}$ Las mujeres entran en relación con otros, no ya para proteger su propiedad como persona, sino a costa de su persona. Se produce la hipertrofia de la paradoja en tanto que el contrato matrimonial 27 demanda a las mujeres que su humanidad sea tanto negada como afirmada. ${ }^{28}$

Una vez que se firma el contrato social, el estado de naturaleza «es dejado atrás» -como simple recurso teórico que era -. En adelante, ahora ya siempre se estarán entablando relaciones civiles «ya no naturales». Ya no es recurrente el estado de naturaleza como referente, como vara de medir (somos iguales en la sociedad civil porque ya lo éramos en la naturaleza y firmamos el contrato para preservar esa igualdad ${ }^{29}$ ), ya no hace falta ese referente porque ahora se ha instaurado

24 Cfr. Pateman, 1995, op. cit.

25 Cfr. Pateman, 1995, op. cit.

26 Cfr. Pateman, 1995, op. cit.

27 Cuando Lévi-Strauss presenta como arquetipo de intercambio el matrimonio: ¿se trata de un intercambio entre las partes? Esto no es posible cuando sólo está implicado un individuo como propietario de su persona. Será el arquetipo de intercambio entre las partes, efectivamente, como señalaremos más adelante, en tanto que las partes son los propietarios de su propia persona, a saber: los varones, no un hombre y una mujer.

28 Afirmada para firmarlo, negada por su contenido.

29 Por lo que pudiera terminar de pasar en la naturaleza, o para prevenir lo que pudiera pasar en órdenes políticos distintos al que origina la voluntad general, según los diversos relatos. 
otro recurso: «Somos iguales, como hermanos, por oposición a nuestras mujeres y el significado político de la sociedad civil no viene dado por oposición al estado de naturaleza sino por oposición, desde la sociedad civil, a la esfera privada, donde el matrimonio es la relación central». ${ }^{30}$ Esta oposición (sociedad civil/esfera privada) es la que mantiene el postulado de la igualdad natural respecto a los varones. Los varones son iguales, no entre ellos, sino por oposición a la situación de las mujeres, por tanto ya no es una igualdad natural sino construida a partir de las condiciones estructurales del patriarcado. 31

A saber, el proyecto ilustrado moderno, en tanto que rousseauniano, y heredero del espacio político-ético de la Grecia platónica, es reivindicado, no porque haya fracasado sino porque no ha llegado a existir, al coincidir en el tiempo con el proyecto liberal, pues este proyecto, tras sucesivas revoluciones industriales, consigue secuestrar el espacio político ${ }^{32}$ para que solo haya un orden económico capitalista. El proyecto ilustrado, y nunca realizado, implica, a la vez, una estructura patriarcal que impone a los sexos un orden de dominación. Y esta parte del proyecto ilustrado ?igualmente ilustrado, con todo un proyecto educativo escrito y practicado? sí que fue llevado a cabo en el tiempo de la historia y , además de inaugurar los tiempos modernos con un patriarcado fraternal, facilitó, tal vez, sobremanera, el camino al proyecto liberal y al fracaso de la ciudadanía.

¿Qué queremos decir con esto? Que no fue «mala suerte»-a posteriori- el que la Ilustración fuese patriarcal, ni una cuestión justificable desde el propio contexto moderno: si la Ilustración hubiese sido «ilustrada», como decía Kant -no tiempos de ilustración sino tiempos ilustrados ${ }^{33}$-: si se hubiese tenido en cuenta la propuesta de Wolstonecraft, de Olympe de Gouges, de Condorcet... se habría dado una Ilustración ilustrada - necesariamente feminista- y, tal vez, para lo que a la tradición marxista interesa, habría sido mucho más difícil instaurar un mundo capitalista en el orden de los fenómenos. Una sociedad civil igualitaria, un auténtico Estado de Derecho, una civilización no patriarcal habría resistido ${ }^{34}$ con más fuerza el arrollador huracán que instaura el capitalismo. No por el hecho de que las mujeres sean más fuertes $-\mathrm{u}$ ontológicamente sean algo distinto 35 - sino por otra cuestión de

30 Cfr. Pateman, 1995, op. cit.

${ }^{31}$ La cuestión de la fratría varonil siempre que los varones quieran sigue funcionando. En el espacio laboral las mujeres pueden quedar excluidas por varones de menor categoría, siempre y cuando ellos quieran señalar su pertenencia al mismo grupo simbólico. Véase a este respecto Fraser, 1997.

32 Como señala la tradición marxista.

33 Ahora bien, por motivos muy diferentes a los de Kant, dada la misoginia explícita en muchos de sus textos.

34 A este respecto, cabría señalar otro enfoque: tal vez, no sólo se allanó el camino al orden socioeconómico capitalista, sino que éste, como instrumento de control que se beneficia de la falta de cohesión social, necesitó aliados para poder sofocar las revueltas campesinas y los movimientos heréticos, protagonizados por la unión de hombres y mujeres, que tuvieron lugar a finales de la Baja Edad Media. A este respecto, véase Federici, 2010.

35 Por supuesto, sin desestimar que las mujeres podemos ser igualmente sujetos revolucionarios, puesto que lo hemos sido. 
mayor fuerza ar gumentativa: a nuestro juicio, una sociedad ilustrada - política y éticamente- en tanto que sociedad que no albergue como fundamento una estructura de dominación, es más resistente ante cualquier otra estructura de dominación -en este caso de orden económico como es el sistema capitalista.

Una sociedad patriarcal, por tanto, al resolver las necesidades del «cuidado» 36 feminizándolo invisibiliza las necesidades de un Estado Social. Del mismo modo, un Estado no patriarcal exigiría la existencia de un verdadero Estado Social.

\section{DE LA DOMINACIÓN MASCULINA COMO BARRERA O COMO PUENTE}

Así las cosas, podríamos afirmar lo siguiente: la dominación masculina actúa como barrera para el propio proyecto ilustrado, a la vez que puede articularse como puente para otra estructura de dominación.

Veamos, para entender lo expuesto, la relación con algo parecido, respecto a otro orden de dominación como es la relación establecida entre las distintas etnias a partir de la instauración de la supremacía blanca. El historiador Howard Zinn, en el libro titulado La otra historia de los Estados Unidos de América, así lo señala respecto al mismo período histórico, pero no ya en Europa, sino en América - las colonias americanas en el siglo XVIII-, en el capítulo «Estableciendo la barrera racial»:

«En Nueva York, en 1741, había diez mil blancos en la ciudad y dos mil esclavos negros. El invierno había sido duro y los pobres ?esclavos y hombres libres? habían sufrido mucho. Cuando se declararon una serie de incendios, se acusó a blancos y negros de conspirar conjuntamente. Se produjo una reacción de histeria colectiva en contra de los acusados. Después de un juicio lleno de confesiones forzadas y las terribles acusaciones de los chivatos, ejecutaron a dos hombres blancos y a dos mujeres del mismo color, ahorcaron a dieciocho esclavos y quemaron a trece más en la hoguera.

\footnotetext{
36 «[...] se entiende que la lógica del capital (la lógica de valorización de capital) es una lógica patriarcal, o androcéntrica, en el sentido que se ha desarrollado desde la filosofía feminista, y que define el patriarcado como un sistema ontológico y ético que comprende la civilización en contraposición a la naturaleza, como su dominio progresivo. Se entiende lo plenamente humano como aquello que nos permite desprendernos de nuestras ataduras biológicas, animales. Lo plenamente humano como el trascender la vida, no perpetuarla. En esta deificación de la trascendencia sobre la inmanencia, las esferas económicas que regeneran vida son entendidas como una forma menos evolucionada que las esferas económicas que ponen la vida al servicio de un fin superior: el crecimiento, la producción, el desarrollo, la industrialización... Llámeselo X. La economía de mercado permite colmar deseos, no satisfacer necesidades. Este es el sentido patriarcal que impregna la lógica del capital, que entroniza la trascendencia, la supuesta autosuficiencia del hombre que, a través del mercado, niega su eco-dependencia, su interdependencia con el conjunto social, su condición frágil y vulnerable. Es la épica que se esconde tras la metáfora de la producción e invisibiliza los trabajos de cuidados.» Orozco, AmAiA: Diagnóstico de la crisis y respuestas desde la economía feminista. Este texto está basado en la ponencia presentada en las XII Jornadas de Economía Crítica «Los retos de la ciencia económica ante la crisis» (Zaragoza, 11 al 13 de febrero de 2010). (El subrayado no es nuestro.)
} 
Sólo había un temor más profundo que el temor a la rebelión negra en las nuevas colonias americanas. El temor a que los blancos descontentos se unieran a los esclavos negros para derrocar el orden existente. En los primeros tiempos de la esclavitud y antes de que el racismo se hubiera atrincherado como actitud mental, mientras a los criados blancos contratados se les trataba igual de mal que a los esclavos negros, existía la posibilidad de esa cooperación.

Por lo tanto se tomaron medidas en ese sentido. En aproximadamente el mismo período en que la Asamblea de Virginia aprobaba los códigos para la esclavitud, con su disciplina y sus castigos, Edmund Morgan escribía:

Habiendo proclamado la clase dirigente virginiana que todos los hombres blancos eran superiores a los negros, acto seguido ofreció a sus inferiores sociales (pero blancos) ciertos beneficios que antes se les habían negado. En 1705 se aprobó una ley que obligaba a los amos a dar 350 kilos de maíz, treinta chelines y un fusil a los criados blancos cuando vencían sus contratos, mientras que las mujeres recibían 500 kilos de maíz y cuarenta chelines. A los criados recién liberados se les daba, además, 50 acres de terreno.

Morgan concluye: una vez que el pequeño colono se sintió menos presionado por los impuestos y empezó a prosperar un poco, se volvió menos inestable, menos peligroso, más respetable. Empezó a ver a su vecino mayor no como un extorsionista sino como un protector poderoso de sus intereses comunes.

Ahora se nos aparece una compleja telaraña de hilos históricos para enredar a los negros en el mundo de la esclavitud en América: la desesperación de los colonos hambrientos, la especial indefensión del africano desarraigado, el poderoso incentivo del beneficio para el negrero y el colono, la tentación del rango superior para los blancos pobres, los controles complejos contra la huida y la rebelión, el castigo legal y social del colaboracionismo entre negro y blanco. Hay que insistir en que los elementos de esta telaraña son históricos, no «naturales». Esto no significa que se puedan desenmarañar ni desmantelar con facilidad. Sólo quiere decir que existe la posibilidad de algo diferente, en condiciones históricas que todavía no se han dado. Y una de estas condiciones sería la eliminación de esa explotación de clase que ha hecho que el blanco pobre aspire a pequeñas subidas de rango social, cosa que ha impedido la necesaria unidad entre negro y blanco para la rebelión conjunta y la reconstrucción.»37

Lo que nos lleva a señalar esta extensa cita en relación con lo expuesto anteriormente, no es la idea de establecer una analogía en términos marxistas de clase, sino simplemente llamar la atención sobre cómo la paz social, para un orden de dominación, como es el sistema racista de esclavitud, se instaura a costa de generar una guerra civil entre los blancos y los negros, en el sentido de que establece una distinción ontológica, que permite instaurar un sentimiento «natural» de superioridad blanca fuertemente rentable en términos económicos para el sistema. En este caso, por tanto, la paz social aparente surge a partir de un orden social no igualitario.

37 Zinn, 1999: 38-39. (El subrayado es nuestro.) 
Asimismo, creemos que el patriarcado instaura «paz social»: a saber , como señala Rousseau, la familia es el orden de la sociedad civil y como veremos que señala igualmente Lévi-Strauss -o ya hiciera Freud - que si bien previene la guerra, provocada por la endogamia, frente a la paz, asegurada por la exogamia, esto sucede al introducir como regla del juego el intercambio de mujeres, por tanto, desde la perspectiva feminista, esto sucede a partir de un orden, claramente, de dominación masculina.

Una de las consecuencias de ese orden de dominación masculina es producir la sensación de igualdad entre los varones (ya sean superiores o inferiores-entre sí-) respecto a las mujeres: lo que puede llegar a provocar el que se posponga la resistencia a ese otro orden de dominación-el económico.

$\mathrm{Al}$ orden capitalista le es indiferente contratar a un blanco, a un negro o a un paquistaní, pero no le es indiferente que en el ambiente se respiren sentimientos de justicia e igualdad o que se respiren sentimientos reaccionarios, xenófobos y de exclusión. ${ }^{38}$

La reseña que podría resumir lo expuesto sería la que expusiese todos estos proyectos contractualistas como pactos entre varones, el grupo de los varones sí se va ampliando, a posteriori, a lo largo de la historia, desde la Grecia clásica en donde solo participaban los varones libres, hasta la Francia revolucionaria donde participarían, en principio, todos los hombres blancos. Así se escribe la civilización occidental; una civilización radicalmente patriarcal (por lo de patriarcal que hay en sus raíces). Cuenta de ello valga el ejemplo clásico muy ilustrativo de este pacto, expuesto en el orden de la antropología, como el tan manido paso de la naturaleza a la cultura, en lo que ha sido la obra estructuralista por excelencia de Lévi-Strauss: obra que termina por dar el carácter de «universal» al histórico pacto entre varones -el matrimonio-. Veamos, brevemente, a qué nos referimos.

\section{GUERRA Y PAZ EN LÉVI-STRAUSS}

Para Lévi-Strauss, el paso de la naturaleza a la cultura se institucionaliza a partir de la ley de la prohibición del incesto o ley de la exogamia. Nuestro autor añade que es la única ley social que no siendo natural tiene carácter universal.

La ley de la prohibición del incesto es el cómo la naturaleza trasciende a la cultura:

«Esta ley tiene el único carácter de regla social que, como las leyes de la naturaleza, es universal. La prohibición del incesto señala la línea divisoria entre naturaleza y cultura o civilización. La ley es el medio a través del cual la naturaleza se tras-

$38 \mathrm{Al}$ orden capitalista, y a la ideología liberal, no le es indiferente que la clase obrera del sur de Francia vote a Le Pen, o, por ejemplo, a un frente libertario anarquista... 
ciende. Una vez que la exogamia es la regla, los hombres deben encontrar a sus esposas fuera de su propio grupo social (o familia).» 39

Lévi-Strauss afirma que la ley de exogamia «instituye sobre la base única posible el libre acceso para cada individuo a las mujeres del grupo... todos los hombres están en igualdad de condiciones de competir por todas las mujeres [...] todos los hombres pueden obtener una mujer (esposa), uno de los "bienes par excellen$c e " 40$... sin el cual la vida es imposible, o al menos, se reduce a las peores formas de abyección.» ${ }^{41}$

Efectivamente, sin ese bien, la vida se reduce a la peor de las vidas: la peor de las vidas para los hombres, porque si eso no fuese así, si las mujeres no fuesen bienes par excellence, estaríamos en un orden social no-patriarcal, donde no habría dominación masculina, y eso para algunos varones, incluido Lévi-S trauss, puede resultar abyecto.

El matrimonio, o el intercambio ordenado de mujeres, que da igual posibilidad de acceso sexual a todos los hombres, es el intercambio original que establece la cultura y la civilización. Una vez que la cultura ha sido creada, las mujeres cesan de ser «estimulantes naturales» y se convierten en signos de valor social. LéviStrauss pone el acento en que (como el lenguaje) la ley de la exogamia crea lazos entre los hombres, se tornan cuñados, se constituyen y se afianzan los lazos comunitarios (fraternales). 42

La mujer, en tanto que objeto de intercambio, no puede figurar como una de las partes; por consiguiente, como señala Pateman, el matrimonio es el arquetipo de intercambio, lo es entre los hombres, no entre los sexos. La relación que establecen los hombres, en el momento del pacto, se desarrolla, así lo dice Lévi- Strauss, «en igualdad de condiciones»; una vez más, tenemos como correlato la igualdad de los hombres -no ya entre sí- sino por oposición a las mujeres.

Nuestro autor narra las condiciones estructurales del patriarcado, por eso es interesante su análisis 43 ; sin embar go, él añade «yo no tengo la culpa de que las

39 LÉVI-STRAuss, ClAude: Estructuras elementales del parentesco, citado en Pateman, 1995: 156, op. cit.

40 «El tabú del incesto, en el que Lévi-Strauss ve el acto fundador de la sociedad, en la medida en que supone el imperativo del intercambio entendido como comunicación equivalente entre los hombres, es el correlato de la institución de la violencia mediante la cual las mujeres son negadas en cuanto que sujetos del intercambio y de la alianza que se establecen a través de ellas, reduciéndolas sin embar go al estado de objetos o, mejor aún, de instrumentos simbólicos de la política masculina. » (Bourdieu, 2000: 60) (El subrayado es nuestro ).

41 LÉvi-Strauss, Claude: Estructuras elementales del parentesco, citado en Pateman, 1995, op. cit., p. 156.

42 Pateman, 1995, en op. cit., p. 156.

$43 \ll[\ldots]$ El lugar para empezar a desenredar el sistema de relaciones por el cual las mujeres se convierten en presa de los hombres está en las obras, que se superponen, de Claude Lévi-Strauss y Sigmund 
cosas sean como yo las estoy contando», efectivamente, pero sí tendrá algo que ver con la posibilidad de ser, él mismo, feminista o no. Lévi-Strauss reduce a una cuestión semiológica ${ }^{44}$ lo que no deja de tener un significado claramente político.

El matrimonio pasa a ser la institucionalización de la prohibición del incesto, por tanto, el paso a la cultura tiene que ser un intercambio entre hombres de distintas familias (ley de la exogamia), a saber: es el intercambio original, en donde se da acceso ordenado a las mujeres. ¿A qué llamamos, entonces, civilización? No al reparto de recursos de manera justa, al espacio de la política... sino a la civilización patriarcal, es decir, al reparto de mujeres, reparto que crea lazos entre los hombres, lazos comunitarios fraternales. En realidad ¿qué está exponiendo Lévi-S trauss, de viaje por el mundo? Algo parecido a lo que sucedió en su país de origen en 1789. Es de nuevo la paz social -paz para los hombres -, frente a la guerra ?guerra no declarada a las mujeres -.

Lévi-Strauss, señala, insistimos, sin sacar conclusiones políticas: «El verdadero propósito del matrimonio es tanto conseguir una esposa ?y su trabajo? como procurarse cuñados», 45 y la finalidad de ello es fundar la paz social frente a la guerra entre familias.

La división sexual de trabajo es el correlato de la prohibición del incesto, conlleva la misma lógica de ordenación de la realidad, pues diferencia lo que se debe hacer de lo que no. Ambas instancias son culturales, no son naturales, pero al ser universales son enteramente necesarias porque son las reglas que configuran el paso de la naturaleza a la cultura, y la posibilidad de que haya sociedad. Bien, ante esto, podríamos añadir lo siguiente: la ley de la exogamia, como intercambio de mujeres por parte de hombres, y la división sexual del trabajo, como la instauración de la dependencia recíproca entre los sexos, son la legitimación fenoménica de la estructura social patriarcal, es decir, existen en tanto que existe patriarcado, y

Freud. La domesticación de las mujeres, bajo otros nombres, está lar gamente estudiada en la obra de ambos. Leyéndolas, se empieza a vislumbrar un aparato social sistemático que emplea mujeres como materia prima y modela mujeres domesticadas como producto. Ni Freud ni Lévi- Strauss vieron su propio trabajo a esta luz, y ciertamente ninguno de ellos echó una mirada crítica al proceso que describen; por lo tanto, sus análisis y descripciones deben ser leídos como Marx leyó a los economistas políticos clásicos que lo precedieron [...]. Freud y Lévi- Strauss son en cierto sentido análogos a Ricardo y Smith: no ven las implicaciones de lo que están diciendo, ni la crítica implícita que su obra es capaz de generar bajo un ojo feminista. Sin embargo, proporcionan los instrumentos conceptuales con que podemos constituir descripciones de la parte de la vida social que es la sede de la opresión de las mujeres, las minorías sexuales y algunos aspectos de la personalidad humana. [...] » (Rubin, 1986, p. 96-97)

44 « [...] La lectura estrictamente semiológica que, al concebir el intercambio de las mujeres como relación de comunicación, oculta la dimensión política de la transacción matrimonial, relación de fuerza simbólica que tiende a conservar o a aumentar la fuerza simbólica, y la interpretación puramente "economicista", marxista o no, que, confundiendo la lógica del modo de producción simbólico con la producción propiamente económica, trata el intercambio de las mujeres como un intercambio de mercancías, tienen en común ignorar la ambigüedad esencial de la economía de los bienes simbólicos» (Bourdieu, 2000, p. 61).

45 Cfr. Lévi-Strauss, 1974, en op. cit. 
son las instancias que ordenan una cosmovisión de la realidad, enteramente arbitraria, pero muy, demasiado, extendida. Estos dos fenómenos, tanto la prohibición del incesto [con su consecuente ley de la exogamia]-intercambio de mujeres por parte de hombres?, y la división sexual del trabajo - dependencia entre los sexos - responden a motivos sociales y económicos, y ante todo simbólicos, de un orden social de dominación que llamamos patriarcado ${ }^{46}$.

Así las cosas, el matrimonio no es ni puede ser un asunto privado, sino que es un asunto que estructura la sociedad civil y se sella públicamente. A esta afirmación de Lévi-Strauss hay que añadir, por parte del feminismo, que lo que verdaderamente es un asunto político y público es la situación de las mujeres en este entramado $^{47}$. Y lo es en las sociedades tribales, en las sociedades modernas y en la rudeza especular de nuestras sociedades apologéticas de la hipertrofia capitalista y consumista.

\section{A MODO DE CONCLUSIÓN}

Expuesto el fracaso del proyecto de la ciudadanía, fracaso no a posteriori, en el discurrir de la historia, que también, sino fracaso a priori, por asentarse sobre la exclusión de las mujeres. Y señalada la ficción del contrato, en tanto que el contrato sexual de dominación constituye el «reverso tenebroso» 48 de dicho proyecto ilustrado. Además del interés fundacional de dicha ficción para otros órdenes sociales, como el capitalismo. Vemos cómo la paz social, pactada entre los varones ?a la luz de los análisis estructuralistas de Lévi-S trauss- y dotadora de realidad para el orden civil -al entrañar en el mismo sentido, la guerra no declarada a las mujeres y por tanto, un orden de dominación-, alumbra la condición de posibilidad para perpetuar las desigualdades sociales entre los individuos que constituyen dicha sociedad. No deberíamos desestimar ${ }^{49}$ los efectos reaccionarios que producen en el mundo las estructuras de dominación, por mucho que la fuerza de la costumbre las haga pasar como instituciones históricas, inamovibles ?en tanto que han existido desde siempre.

\footnotetext{
46 No renunciamos al término patriarcado entroncando, así, con el recorrido teórico de la autora que aparece como principal fuente de nuestro trabajo, Pateman. De igual manera, compartimos así las herramientas conceptuales de la rigurosa obra de la filósofa feminista Celia Amorós. Comentar las propuestas alternativas al término ?y sus implicaciones?, como las que propone Rubin, (1986) sería objeto de otro artículo.

47 « [...] Las mujeres son entregadas en matrimonio, tomadas en batalla, cambiadas por favores, enviadas como tributo, intercambiadas, compradas y vendidas. Lejos de estar limitadas al mundo "primitivo", esas prácticas parecen simplemente volverse más pronunciadas y comercializadas en sociedades más "civilizadas". Desde luego, también hay tráfico de hombres, pero como esclavos, campeones de atletismo, siervos o alguna otra categoría catastrófica, no como hombres. » (Rubin, 1986, p.111)

48 Cfr. Amorós, 1997.

49 De lo expuesto se sigue, que debiera ser prioridad para los movimientos anticapitalistas el análisis feminista como punto de partida y no una mera declaración de intenciones.
} 
Llegando a este punto expositivo, cabe ya preguntarse por la confrontación que originó dicha exposición. ¿En qué medida tiene relación el fracaso de la ciudadanía, la ficción del contrato social y la inverosimilitud del proyecto ilustrado, con la mercantilización de los cuerpos, y sus derechos, en nuestro escenario globalizado y violentamente convertido en espectáculo ${ }^{50}$ ? A nuestro juicio, la reflexión pendiente para poder responder a lo cuestionado sería la que se hiciese car go de lo expuesto junto con esos fracasos: la rentabilidad para el orden establecido de que los proyectos emancipatorios lleven «bicho dentro»-como dice la filósofa Celia Amorós- es altamente conveniente para el poder establecido, y puede llevarnos a confusiones a la hora de defender nuestros derechos. (T odo el mundo quiere defender sus derechos, pero la reflexión sobre cuáles sean éstos no es baladí.)

Sin poder entrar en una fundamentación rigurosa, abrimos una línea de debate, siguiendo la tesis de la feminista norteamericana Kathleen Barry:

"Hoy en día, en Estados Unidos, el patriarcado de la familia no puede seguir sosteniendo con eficacia el control sobre las mujeres. La dominación privatizada, cuando el patriarcado crece en torno al matrimonio y la familia, ha perdido su fuerza porque un gran número de mujeres ha accedido a la esfera pública y ha podido ejercer su independencia económica. Las leyes matrimoniales han cambiado hasta el punto de que en la mayoría de los estados las mujeres casadas, en un sentido técnico, ya no son propiedad legal de sus maridos. Pero esto no disminuye la incidencia de los abusos sobre las esposas. [...] La privatización de las mujeres no puede asegurarse por más tiempo mediante la dominación patriarcal que ejerce el matrimonio. La familia se ha visto demasiado expuesta al ámbito público como para ser el lugar del control total sobre las mujeres que caracteriza a las relaciones patriarcales de poder. El cuerpo se ha convertido en el terreno de la dominación, pero no lo ha hecho reemplazando al matrimonio o la familia como lugares de opresión patriarcal sino operando como un terreno que cubre todas las otras condiciones. El cuerpo del que hablo es el de la mujer sexualizada." 51

50 La sociedad del espectáculo aparece como escenario heredado de la tradición francesa situacionista, tradición que acierta en dilucidar unas coordenadas modernas en donde el sistema socio-económico adquiere una impronta ontológica que alcanza tanto a lo que existe como a lo que se piensa. Bajo esas coordenadas, cada vez más difíciles de disolver, se impone el orden de la apariencia frente al orden del ser: "El espectáculo, entendido en su totalidad, es al mismo tiempo el resultado y el proyecto del modo de producción existente. No es un suplemento del mundo real, una decoración sobreañadida. Es el núcleo del irrealismo de la sociedad real. Bajo todas sus formas particulares -información o propaganda, publicidad o consumo directo de diversiones-, el espectáculo constituye el modelo actual de vida socialmente dominante. Es la omnipresente afirmación de una opción ya efectuada en la producción, y su consiguiente consumo. La forma y el contenido del espectáculo son, del mismo modo, la justificación total de las condiciones y de los fines del sistema existente. El espectáculo es también la permamente presencia de esta justificación, en cuanto ocupación de la parte primordial del tiempo de vida que transcurre fuera del ámbito de la producción moderna". Debord, 1999, p. 39, \& 6).

Respecto a lo que nos ocupa, la producción simbólica de dicho sistema funciona como cadena de transmisión de los valores patriarcales. El intercambio de mujeres se redimensiona forzosamente bajo su industralización, la cual puede aparecer como aparentemente inocua, neutra, como mero espectáculo consumible que recibe su legitimación en el orden del ocio. A este respecto véase Sheyla Jeffreys ( 1996).

51 BARRY, KATHLEEN (1994, p. 302 ) 
En Occidente, el patriarcado moderno comienza a debilitarse a partir de los años setenta, gracias al movimiento feminista, y deriva así en una nueva configuración del patriarcado. La nueva estructura patriarcal ya no consistirá sólo en la reclusión de las mujeres en el espacio doméstico - contrato sexual moderno- sino también, y sobre todo, en la reclusión de las mujeres en su propio cuerpo. El cuerpo sexualizado de las mujeres es el lugar en donde sucede la reconversión industrial de las condiciones contemporáneas del patriarcado. El cuerpo de las mujeres vuelve a sufrir la carga identitaria que se disputaran los varones de distintas representaciones políticas y culturales, es decir: antes, el cuerpo de las mujeres funcionaba para los varones como seña simbólica de la esposa y madre, ahora la feminidad normativa impone otro modelo, compatible con el anterior , el de la sexualización del cuerpo de las mujeres.

En las sociedades occidentales, donde el contrato matrimonial deja de tener los efectos inmediatos que le supuso la Ilustración, pues el feminismo ha desmontado una y mil veces la dominación subyacente a dicho contrato, ¿adquirirá más fuerza otro contrato sexual? ¿T omarán el relevo de la producción patriarcal, de manera casi industrializada, grandes plataformas comerciales, de ocio y espectáculo, destinadas a la compra de los cuerpos mercantilizados?

Así las cosas, ¿la compra de cuerpos mercantilizados se manifiesta como subversiva? ¿O reproduce efectos ciertamente reaccionarios, ${ }^{52}$ ficcionando igualdad entre los que consumen por oposición a los cuerpos consumidos? ¿El contrato sexual que selle esta relación sellará un nuevo fracaso a priori de la ciudadanía...?

¿Se puede defender un contrato desde el que se pacte la compra de los cuerpos? ¿Es ese un derecho no patriarcal por el que debemos luchar las feministas? ¿No se tratará, una y mil veces, de un pacto entre varones, ante el cual tenemos dos opciones: empoderarnos desde dentro, o desconfigurar las coordenadas de ese pacto disolviéndolo para ni siquiera ingresar en él, y que el empoderamiento se deduzca de nuestra capacidad para no ser compradas, para ser libres? A este respecto, es

52 Tal vez podríamos señalar como punta del iceberg, ciertos locales convertidos en lugares de concurrencia para muchos varones, como son los locales que brillan con luces de neón, a los lados de las autopistas nacionales y las carreteras secundarias, en los polígonos industriales, a lo lar go del mundo rural, y a lo ancho de las ciudades. A estos locales acuden, en su mayoría, varones, representantes de todo el espectro social, para acceder a la compra de cuerpos mercantilizados -en su mayoría cuerpos de mujeres "extracomunitarias"- Estos locales son considerados socialmente como lugares de ocio, de relax, muchas veces poniendo colofón a la jornada laboral. En una sociedad descarnadamente consumista, frente a esta representación colectiva de los espacios de ocio, cabría preguntarse: ¿a qué espacios irían los cuerpos de esas mujeres "extracomunitarias" para desahogarse y divertirse después de su jornada laboral?

Aventuramos una pregunta, para la que no tenemos una respuesta definitiva, pero simplemente queremos iniciar una reflexión, en la actual situación, tan crítica para los trabajadores, los polígonos, los pueblos y las ciudades ¿no debieran estar llenos de sindicatos o de asambleas, en lugar de los citados locales? ¿Esos locales están habitados de la misma manera por cuerpos trabajadores? ¿O, tal vez, esos cuerpos ocupan simbólicamente, económica y socialmente lugares distintos? ¿En dichos locales pueden coincidir patrones y trabajadores? ¿Se daría esa coincidencia si se tratase, por ejemplo, de locales sindicales? 
necesario insistir en la siguiente coyuntura: ${ }^{53}$ estar del lado de los cuerpos sexualizados de las mujeres no impide mantener una perspectiva crítica respecto a la institución que mercantiliza dichos cuerpos. Es más, no entendemos de qué otra manera podría hacerse desde el feminismo.

¿No nos encontraremos de nuevo, ya siempre, con el venerable intercambio de mujeres por parte de hombres? ¿Es algo contingente y tangencial que en dicho mercado la demanda de cuerpos de mujeres por parte de varones sea el fenómeno mayoritario? ¿Se puede abstraer en el orden del análisis el carácter sumamente violento de dicho mercado sobre los cuerpos de aquellas mujeres que no quieren ser mercantilizadas? ¿Dicha circunstancia, condenada por todos los colectivos, es capaz de desligarse, aislarse en todo su significado, del resto del fenómeno?

A la luz de estas cuestiones, que simplemente apuntan hacia una reflexión $\quad-\mathrm{a}$ partir de aquí comenzaría otro artículo -, cabe señalar la exposición de Celia Amorós $^{54}$ en lo que podríamos llamar el paso del imaginario patriarcal -de Rousseau- al imaginario libertino -Sade-. Lo que nos llevaría del destino trágico de Madame Bovary al destino aún más trágico de las mujeres de Ciudad Juárez. Desierto de ciudadanía, Ciudad Juárez, se extiende por todos los continentes, llegando a todos los rincones: siempre que una mujer es desprovista de sus derechos...

¿Seremos capaces de reconocer todos esos desiertos de ciudadanía? ¿O las luces de neón de la sociedad del espectáculo cegarán nuestros deseos de libertad, dificultando la capacidad de discernir y el derecho a defendernos a priori de cualquier apropiación patriarcal?

La autodeterminación de los cuerpos fomenta con su ideario la batalla contra la desestigmatización de los cuerpos sexualizados y mercantilizados. Desde ese ideario, la disolución de los estigmas se produciría a partir de la formalización y la aceptación de la mercantilización. Ante esto, y a la luz de lo expuesto, nos preguntamos si la causalidad del fenómeno no será una vez más la inversa. ¿No serán los cuerpos, previamente estigmatizados, ${ }^{55}$ los que en múltiples performances -fuertemente realistas - adquieren la impronta de la mercantilización, siendo, una y mil veces, comprados? ¿Sería legítimo, así las cosas, exigir a priori la desestigmatización de los cuerpos sexualizados, siempre otros, siempre lejanos, siempre nómadas...? ¿Sería un atrevido sueño emancipatorio aunar la lucha hacia la desestigmatización de lo diferente, de lo menos pudiente, menos blanco, menos normativizado... antes, siempre antes, para que su estigma no sirva de imán, de jus-

53 Coyuntura defendida desde la militancia política de mujeres feministas tan combatientes como Rosario Carracedo. También cabe citar el trabajo teórico al respecto de Rosa Cobo.

54 Véase a este respecto AMORÓS, CELIA (2008): Violencia patriarcal en la era de la globalización: de Sade a las maquilas.

55 Cuerpos previamente estigmatizados por la pobreza, el desarraigo, por el devenir vertiginoso de las migraciones... 
tificación, a su puesta en venta en un mercado, históricamente eterno ${ }^{56}$ en el imaginario patriarcal? ¿Podemos soñar, las feministas, con la libertad que se deriva de, por fin, poseer propiedad - propietarias de nuestra persona-independencia e igualdad, en tanto que principios civiles que no están en venta?

¿Podremos firmar la paz de un orden social que no implique la guerra para nadie, por muy distinta, inapropiada, inapropiable... que sea?

\section{BIBLIOGRAFÍA}

Amorós, C elia (1985): Hacia una crítica de la razón patriarcal. Barcelona: Ed. Anthropos.

-, coord. (1994): Historia de la Teoría Feminista. Madrid: DGM. UCM.

-, dir. (1995): 10 palabras clave sobre Mujer. Navarra: Ed. Verbo Divino.

- (1997): Tiempo de Feminismo. Madrid: Cátedra, Colección Feminismos.

-, ed. (2005): Teoría Feminista: de la Ilustración a la globalización. Madrid: Minerva Ediciones.

- (2008): Mujeres e imaginarios de la globalización. Argentina: Ed. Homo Sapiens.

BARRY, KATHLEEN (1994): Teoría del feminismo racial: política de explotación sexual.

En Amorós, C. (coord.): Historia de la Teoría Feminista. Madrid: DGM. UCM.

Bourdieu, Pierre (2000): La dominación masculina. Barcelona: Ed. Anagrama.

Debord, Guy (1999): La sociedad del espectáculo. Valencia: Ed. Pretextos.

Deraismes, M ARIE (2010): Eva en la humanidad. Madrid: Ed. Fundación María Deraismes.

FALUDI, SUSAN (1993): Reacción. La guerra no declarada contra la mujer moderna. Barcelona: Ed. Anagrama.

FERNÁNDEZ LiRia, A LBERTO (2011): «De la Psicoterapia a la Economía». www Rebelión.org, 10-15-2011.

Federici, Silvia (2010): Calibán y la bruja. Madrid: Ed. Traficantes de Sueños.

FraSER, N ANCY (1997): Iustitia Interrupta. Bogotá: Siglo del Hombre Editores, Universidad de los Andes, Facultad de Derecho, Colección Nuevo Pensamiento Jurídico.

Garaizabal, Cristina (2007): Presentación. En AA. vv., Los pasos invisibles de la prostitución. Barcelona: Ed. Virus.

HaVelock, ERIC A. (1994): Prefacio a Platón. Madrid: Ed. Visor, Literatura y Debate Crítico.

Jefrreys, S heila (1996): La herejía lesbiana. Madrid: Ed. Cátedra, Colección Feminismos.

KANT, INMANUEl (1978): ¿Qué es la Ilustración? En Filosofía de la Historia. México: Ed. Fondo de Cultura Económica.

56 Dicho fenómeno no es natural, pero es universal en la medida en que aparece en todas las sociedades. Ahora bien, tal vez, debiéramos preguntarnos, ¿no será que aparece no por ser universal, sino porque todas las sociedades en las que aparece son patriarcales? 
Lévi-Strauss, Claude (1974): La familia. En Lévi-Strauss, Claude: Polémica sobre el origen y la universalidad de la familia. Barcelona: Ed. Anagrama, Cuadernos Anagrama.

Locke, John (2002): Segundo Tratado sobre el Gobierno Civil. Madrid: Ed. Tecnos.

Pateman, Carole (1995): El contrato sexual. Barcelona: Ed. Anthropos.

Puleo, Alicia, ed. (1993): La Ilustración Olvidada. La polémica de los sexos en el siglo XVIII. Barcelona: Ed. Anthropos.

Rousseau, J EAN-Jacques (1995): Emilio, o De la educación. Madrid: Alianza Editorial.

Rubin, GAYLE (1986): El tráfico de mujeres: notas sobre la "economía política" del sexo. Revista Nueva Antropología, $\mathrm{n}^{\circ}$ 030. Universidad Nacional Autónoma de México. P. 95-145.

Wollstonecraft, Mary (2000): Vindicación de los Derechos de la Mujer. Madrid: Ed. Cátedra, Colección Feminismos.

ZINN, HowARD (1999): La otra historia de los Estados Unidos. Hondarribia: Ed. Hiru. 